\title{
Nas sombras do presente: um estudo dos dispositivos políticos e estéticos pós- modernos
}

\author{
Paulo César S. de Oliveira ${ }^{1}$ \\ Larissa Moreira Fidalgo ${ }^{2}$
}

\begin{abstract}
Resumo: O pós-modernismo, como uma corrente de saber presente nos mais diversos campos, tem despertado a atenção de muitos críticos que se posicionam de diferentes maneiras frente ao problema. Acusado de ser uma arte infundada e superficial, divertida e caudatária, nas palavras de Terry Eagleton (1998), esse fenômeno político e cultural abarcou as instâncias de ruptura e questionamento do saber dominante, provocando intensas transformações nos mais diversos campos. E é justamente nessa rede de transformações autoconscientes que desafiam a Teoria Literária em buscar novas metodologias capazes de lidar com esse dispositivo político e estético que o presente trabalho fixa suas raízes. Mergulhando nas sombras do presente, estabeleceremos uma análise que visa contemplar as principais e polêmicas questões suscitadas pela poética no pós-modernismo através do estudo crítico do romance Nove noites, do brasileiro Bernardo Carvalho. Verificando a existência de uma relação de semelhança entre os discursos literário e histórico, sem negligenciar suas particularidades, investigaremos de que maneira, ao constituírem-se como formas narrativas, ambos mantêm uma relação especial com o tempo passado, dando forma à nossa experiência temporal.
\end{abstract}

Palavras-chave: Pós-modernismo. Literatura e História. Cânone.

\section{Introdução}

\begin{abstract}
O que está prestes a ruir não é apenas nosso "olhar" sobre a literatura, mas o próprio espaço a partir do qual a apreendemos. A metáfora ótica (nosso "olhar", nossa "visão" da literatura) não é isenta de riscos, pois permite pensar que haveria um objeto estável a literatura - cujas propriedades poderíamos melhor apreender se melhorássemos nossos instrumentos de percepção. Isso deixa de lado o fato de que esse "objeto" se transforma de acordo com os instrumentos.
\end{abstract}

Dominique Maingueneau

Entrar em um território no qual as fronteiras, acreditava-se, estavam bem delimitadas e as respostas aos questionamentos eram capazes de tranquilizar um espírito inquieto e fervoroso, nem

\footnotetext{
${ }^{1}$ Paulo César S. Oliveira é Doutor e mestre em Poética pela UFRJ e professor adjunto de Teoria Literária da UERJ e professor titular da Uniabeu. Publicou o livro Poética da distensão (Manaus: Muiraquitã, 2010) e organizou a coletânea Memória e identidade (Rio de Janeiro: Edições Galo Branco, 2011). Coordena o projeto de Iniciação Científica (PIBIC UERJ) intitulado Viagens reais e imaginadas: história, ficção e autobiografia nas obras de Bernardo Carvalho e Bruce Chatwin. E-mail: paulo.centrorio@uol.com.br.

${ }^{2}$ Graduanda do curso de Letras da UERJ e bolsista do Programa Institucional de Bolsas de Iniciação Científica da mesma instituição (PIBIC UERJ).E-mail: larissa_mf@oi.com.br.
} 
sempre é uma atitude sensata, diriam os românticos. Entretanto, diante de um conjunto representativo de modelos e instituições que, de certo modo, controlavam e dirigiam a constituição dos objetos e seus procedimentos de análise, a exposição ao perigo é antes um mal necessário do que um bem a ser preservado. É justamente nesse contexto transgressor e autoconsciente dos paradigmas da ordem e da origem, radical e frequentemente assinalado como infundado, superficial e niilista, que a poética do pós-modernismo, objeto de nossas considerações, encontra-se inserida.

Revisitando a historiografia literária e o estatuto da crítica, a arte pós-moderna se volta para uma atividade paradoxal e de distante solução: mergulhar nas sombras do mundo histórico para compreender, ainda que de maneira fragmentada, os sistemas de signos que conferem forma a nossa experiência temporal: em outras palavras, para as convenções das instâncias narrativas. Nesse contexto, desafiando e subvertendo nosso conhecimento literário e histórico, a fícção pósmoderna investe nas incompreendidas questões históricas, desmaterializando as clássicas fronteiras que separavam a ficção e a história através do reconhecimento dos limites do relato. Sem desconsiderar, entretanto, o conhecimento histórico, fatual, a cultura pós-moderna sugere que revisemos nossas concepções, rearticulando os pressupostos idealistas da crítica descritiva, direcionando nossa atenção para os sistemas culturais e para as construções ideológicas das formas narrativas, em outras palavras, para o discurso, objeto de significação das nossas experiências. Por conseguinte, ao introduzir acontecimentos históricos em um universo ficcional, a literatura pós-moderna problematiza e questiona os pressupostos históricos de "objetividade, neutralidade, impessoalidade e transparência da representação" (HUTCHEON, 1991, p. 125).

Nesse cenário, muitos críticos contestam a existência de tais aspectos em obras literárias anteriores ao advento dessa manifestação artístico-política irresoluta e contraditória. Ao considerarmos aquilo que conhecemos por literatura como sendo uma instância discursiva polifônica e polissêmica, o inter-relacionamento de textos e discursos de diferentes áreas não é um procedimento inovador, obviamente. O original, aqui, não é a mera intercomunicação apreendida superficial e estatisticamente sobre o tecido da criação literária, sua existência única na qual se desdobrava a história da obra, como defendia Walter Benjamin (1985, p.167), mas a estrutura, nem sempre visível a olho nu, que sustenta a organização criativa de nossa experiência temporal sob os signos dos atos de fingir. Em outras palavras, "o que é novo é que essa assimilação se realize em termos de reelaboração ilimitada da forma e do sentido, em termos de 
apropriação livre, sem que vise o estabelecimento de um sentido final" (MOISÉS, 2005, p. 63) ideológico, homogeneizante, monológico e dogmático.

A inexistência do ponto final no discurso poético, confirmada pela relação do pósmodernismo com o tempo a "que este adere através de uma dissociação e um anacronismo" (AGAMBEN, 2010, p. 59), promove rupturas violentas entre o material e sua representação, na medida em que a linguagem configura e transfigura a rede conceitual das ações no jogo da referência, nos conclamando a (re) pensar criticamente o modo aurático da obra literária. Conforme defendido por Benjamin (1985), em seu famoso ensaio acerca das novas condições de produção artística na era da reprodutibilidade técnica, o capitalismo provou intensas transformações nos meios culturais, principalmente na arte. Com a reprodução em massa da escrita, nos afastamos progressivamente do espaço histórico no qual a obra foi produzida e, consequentemente, do seu ser autêntico que detém e legitima seu caráter representativo. Nesse viés benjaminiano, que incorre no risco de rondar o dogmatismo e autoritarismo românticos ao desconsiderar a dimensão pragmática de todo e qualquer discurso, só poderíamos decifrar o código secreto, o sentido de verdade de um mundo considerado transitivo se voltássemos ao "aqui e agora da obra de arte, sua existência única, no lugar em que ela se encontra" (BENJAMIN, 1985, p. 167).

Entretanto, o fato é que "sua verdade não é uma adequação a um referente exterior, mas o fruto de sua própria organização, resposta provisória da linguagem a uma pergunta sempre aberta” (MOISÉS, 2005, p. 33). Desse modo, essa possível ortodoxia benjaminiana não é capaz de compreender inteiramente as urgentes questões suscitadas pela literatura enquanto discurso de possibilidades. Em prol da heterogeneidade discursiva e da multiplicidade de sentidos, nos distanciamos da ideia de uma verdade absoluta e estrutural, isolada no tempo e apartada de suas configurações históricas. Tal verdade, sob esse prisma redutor, poderia ser alcançada mediante a adoção dos clássicos métodos de seleção e exclusão da História enquanto disciplina de pretensão a uma verdade objetiva e incontestável. Esse distanciamento será marcado pelo retorno da literatura às questões marginalizadas pelo paradigma tradicional da historiografia, evidenciando que o lugar da construção do objeto "História" não é um passado utopicamente apreendido tal como ele foi, um espaço homogêneo e estável, mas o escuro do presente que aproxima o vivido e o não-vivido na dialética passado/presente, presente/passado. Sob esse ângulo, seria “irrecuperável toda a imagem do passado que ameaça desaparecer com todo o presente que não 
se reconheceu como presente intencionado dela" (BENJAMIN, 2008, p. 11). Atuando no elemento histórico, aquilo que Hegel (Apud AGAMBEN, 2010, p. 32) cunhou por positividade, a poética do pós-modernismo (e sua relação com história) nos mostra, conforme D. W. Winnicott, como um "objeto transicional" (apud LIMA, 2006, p. 289), ao rearticular a realidade e suas relações de poder, é capaz de preencher as lacunas da História.

É importante ressaltar, portanto, que não estamos polarizando, defendendo a existência de "verdades mundanas e historicamente mutáveis, ao lado de uma classe superior de verdades absolutas" (EAGLETON, 2003, p. 148). Não se trata de desvendar aquilo que estava encoberto na realidade, visto que a própria noção de "real" "tornou-se" contestável, mas de desnaturalizar a articulação histórica de um significado único e exclusivo, revelando, assim, novas relações que compreendem um "conjunto das crenças, das regras e dos ritos que numa determinada sociedade e num determinado momento histórico são impostos aos indivíduos pelo exterior" (AGAMBEN, 2010, p. 30-31).

Nesse sentido, sem operar uma redução, mas agindo no campo dinâmico da desconstrução, a poética do pós-modernismo, aqui lida como pro-vocação à Teoria Literária, nos obriga a abandonar o terreno aparentemente plano e estável no qual, confortavelmente, costumávamos edificar nossos instrumentos de percepção. Com isso, nos força a estabelecer um campo discursivo no qual "dito e dizer, texto e contexto são indissociáveis" (MAINGUENEAU, 2001, p. $\mathrm{X}$ ). Operando no limite entre a crítica e a escritura, esse "novo" horizonte nos permitirá - o que não significa que estaremos isentos de sofrimento - descortinar as convenções simbólicas, culturais e políticas que estão por trás de toda construção histórica, seja ela literária ou pertencente ao campo da historiografia. Conforme observado pela teórica canadense Linda Hutcheon (2005, p. 2):

[...] it seems reasonable to say that the postmodern's initial concern is to denaturalize some of the dominant features of our way of life; to point out that those entities that we unthinkingly experience as 'natural' (they might even include capitalism, patriarchy, liberal humanism) are in fact 'cultural'; made by us, not given to us. Even nature, postmodernism might point out, doesn't grow on trees".

\footnotetext{
3 "Parece razoável dizer que a preocupação inicial do pós-moderno é de desnaturalizar algumas das características dominantes do nosso modo de vida, de salientar que as entidades que inconscientemente experienciamos como 'naturais' são de fato 'culturais', feitas por nós, não dadas para nós. Mesmo a natureza, o pós-modernismo pode apontar, não cresce em árvores" (Nossa tradução).
} 
Diante desse cenário de desconstrução do caráter temporal da experiência humana que urge por uma "reelaboração da teoria para responder a condições claramente novas, em vez de ser a aplicação obediente de um dado corpo de conhecimento", como bem observou Terry Eagleton (2011, p. 56), em sua análise sobre os estudos culturais e o pós-modernismo, revisitaremos e reavaliaremos criticamente, nas questões que se seguem, as premissas dominantes da Teoria Literária tradicional e seus dispositivos estéticos e políticos homogeneizantes em contraste com as profundas mudanças ocorridas no campo literário e cultural a partir da década de 80, pois, corroborando a perspectiva de Hutcheon (1991, p. 12), a poética do pós-modernismo, aqui ilustrada pela ficção, reflete a crise dos estudos literários:

[...] que estão presos entre a urgente necessidade de essencializar a literatura e sua linguagem num repositório textual exclusivo, vasto e fechado, e a contrastante necessidade de proporcionar "relevância" à literatura, localizando-a em contextos discursivos mais amplos. Tanto a arte como a teoria pós-modernas são a encarnação dessa própria crise, não ao tomarem um dos partidos, mas as sobreviverem à contradição de ceder a essas duas necessidades.

Embora introdutório do ponto de vista de uma análise que requer abordagens mais profundas, considerando a longa e profícua jornada que deve ser percorrida ao nos aventuramos no labiríntico universo pós-moderno, esse presente artigo configura-se com um espaço de "terceira-margem", ao entrever na História um corpo sólido que se desmanchou nas vértebras do presente. Assim, na tentativa de abranger um rol mais amplo e plural de conceitos e questões, percorreremos dois caminhos que, em coexistência, nos oferecem um panorama dos percalços enfrentados pela crítica hodierna. Primeiramente, analisaremos a pertinência do cânone, ou seja, das análises tradicionais, em uma cultura híbrida, dialógica e metadiscursiva. Em seguida, adentraremos em um universo não menos problemático. Verificando a existência de uma relação de semelhança entre os discursos literário e histórico, como já apontamos anteriormente, mas sem negligenciar suas particularidades, investigaremos de que maneira, ao constituírem-se como formas narrativas, ambos mantêm uma relação especial com o tempo passado, dando forma à nossa experiência temporal através da análise desse aspecto no romance Nove noites, do brasileiro Bernardo Carvalho.

\section{Contextualizando o "pós-modernismo": a análise tradicional e a crítica hodierna}


Nós caminhamos incessantemente entre o objeto e a sua desmistificação, incapazes de lhe conferir uma totalidade: pois, se penetrarmos no objeto, libertamo-lo, mas destruímo-lo; e se lhe deixamos o peso, respeitamo-lo, mas devolvemo-lo ainda mistificado.

Roland Barthes

O Pós-modernismo, como uma corrente de pensamento presente nos mais variados campos do saber, tem despertado a atenção de muitos críticos que se posicionam de diferentes maneiras frente ao problema. Na literatura, a contextualização de tal poética ora se impõe como um recrudescimento do fenômeno moderno, através de uma perspectiva temporal e histórica, ora questiona sua relação com o presente, indagando o lócus ocupado por ela em um mundo globalizado, condenado a falar excessivamente do real, como diria Roland Barthes.

Diante dessa problemática, uma das soluções mais frequentes seria pensar cada época literária como reflexo de sua geração, de suas complexidades e diversidades históricas, ou seja, pensar literatura em uma série plural. Assim, a dominante na década de 1980 seria o acirramento do debate sobre a literatura pós-moderna; a de 1990, sobre a chamada geração dos "transgressores". Outros críticos retrocedem no tempo, declarando o problema mais antigo, alguns até explicitando sua aversão ao conceito ou à corrente, ao "fantasma pós-moderno", que, "ainda nos anos 50, começou a correr mundo" (SANTOS, 1987, p. 10).

Discutindo criticamente os conceitos tradicionais de história, tais como continuidade e linearidade, o pós-modernismo abarcou as instâncias de ruptura e questionamento do saber dominante, abrindo espaço para novas marcas identitárias e étnicas, principalmente após a descolonização da África e Ásia no Pós-Guerra. Dessa forma, a ficção contemporânea, com seu caráter multidisciplinar, polifônico e polissêmico reflete as múltiplas possibilidades de discussão do mundo globalizado constituído por novos personagens e novas críticas. Mas as teorias pósmodernas, elas mesmas, seriam alvo também de críticas duras, contundentes.

Nesse contexto de multiplicidade e polêmica expressa, Beatriz Resende (2007) definiu a nova geração como tolerante, alegando que o século XXI introduziu amostras de temas e estilos em coexistência, mas sem a formulação de nenhuma tendência.

Segundo Terry Eagleton (1998, p. 7), “a palavra pós-modernismo refere-se em geral a uma forma de cultura contemporânea, enquanto o termo pós-modernidade alude a um período histórico específico". Seguindo essa linha, a pós-modernidade, contrariando as noções clássicas 
do iluminismo, observa "o mundo como contingente, gratuito, diverso, instável, um conjunto de culturas e interpretações" manifestado no Ocidente como uma nova forma de conceber o mundo capitalista: mundo, este ente efêmero e descentralizado, no qual a indústria tecnológica suprimiu a cultura tradicional e a poética clássica, cedendo espaço à política de identidades.

Contudo, Eagleton (1998, p. 7) funde os conceitos elucidados, pois em um universo tão híbrido, qualquer tentativa de categorização seria inútil para uma arte "superficial, descentrada, infundada, auto-reflexiva, divertida, caudatária, eclética e pluralista", concluindo que o real transfigura-se na irracionalidade, e o racional na irrealidade.

Em vista de imprecisas associações, e divergindo da leitura mais ideológica de Eagleton e algumas de suas generalizações, gostaríamos de abranger um rol mais amplo e plural de conceitos e questões, capaz de explicitar que a crença na superficialidade e na imitação como características da literatura contemporânea nos levará a um túnel obscuro, caso não tomemos certos cuidados.

Em uma cultura plural e fragmentada, o pós-modernismo não pode ser entendido como mero sinônimo de contemporâneo. Karl Erik Schollhammer (2009, p. 9) problematiza essa questão, pois, ao relacionar o termo "pós-moderno" ao "contemporâneo" não estaríamos caracterizando "uma determinada relação entre o momento histórico e a ficção e, mais amplamente, entre a literatura e a cultura?".

Aquilo que desejamos chamar de pós-modernismo é definido por Linda Hutcheon (1991, p. 19-20) como algo "fundamentalmente contraditório, deliberadamente histórico e inevitavelmente político", "que usa e abusa, instala e depois subverte os próprios conceitos que desafia". Sendo uma atividade cultural que pode ser observada em muitas correntes filosóficas atuais, suas contradições se manifestam na concepção pós-moderna da "presença do passado". Ao falar em presença do passado, não se defende um simples regresso da ficção ao passado histórico e literário, recuperando suas representações simbólicas e suas formas estéticas. Ao contrário, o pósmodernismo "não sugere nenhuma busca para encontrar um sentido atemporal transcendente, mas sim uma reavaliação e um diálogo em relação ao passado à luz do presente" (HUTCHEON, 1991, p. 39). Enquanto isso, o contemporâneo se estabelece em torno de inconstantes perguntas sobre o passado histórico e o futuro utópico para concebê-los criticamente:

O passado apenas se presentifica enquanto perdido, oferecendo como testemunho seus índices desconexos, matéria-prima de uma pulsão arquivista de reconhecê-lo e reconstruí-lo literariamente. Enquanto isso, o futuro só adquire 
sentido por intermédio de uma ação intempestiva capaz de lidar com a ausência de promessas redentoras ou libertadoras (SCHOLLHAMMER, 2009, p. 13).

Corroborando a perspectiva de Roland Barthes (Apud AGAMBEN, 2009, p. 58), para quem “o contemporâneo é o intempestivo", entendemos que o verdadeiro contemporâneo é aquele que, a partir da impossibilidade de apreender sua realidade histórica, graças a um deslocamento, graças a sua não identificação com o espaço no qual se encontra inserido, é capaz de captar e retratar a especificidade atual, o presente. O sujeito do presente, por se situar dentro das próprias convenções de um sistema totalizante que deseja subverter, não é representado, necessariamente por essa ideia de realidade homogeneizante. A literatura do presente, nessa perspectiva, se deslocará do centro em direção às zonas marginais que, embora mais numerosa que os já conhecidos "protagonistas" do materialismo histórico, havia ficado invisível para os narradores da História em nome de um progresso até hoje desconhecido. $\mathrm{O}$ ex-cêntrico, portanto, iluminado pelo pós-modernismo, adquire uma nova concepção a partir do reconhecimento de que na realidade estamos inseridos em uma sociedade híbrida, com personagens deslocados na fronteira multicultural contemporânea.

A poética do pós-modernismo desconstrói as ideias de homogeneidade, aludindo aos conceitos clássicos de verdade, razão e objetividade que norteiam as narrativas, questionando esses pressupostos. Dessa forma, podemos pensar a ideia pós-moderna, mais acertadamente, a noção de contemporaneidade, como um momento de deposição dos conceitos do platonismo, e essa demissão é, de várias formas, demarcada pela valorização do simulacro. Conforme Leyla Perrone-Moisés, o platonismo e, posteriormente, o pensamento em torno da noção de representação, intimamente relacionados ao idealismo dos dogmas cristãos, legitimavam a cópia, depreciando, consequentemente, o simulacro. A justificava para tal posicionamento ideológico da filosofia monocêntrica permanece centrada na valorização da cópia-ícone, ou seja, da cópia como imitação fiel das Ideias, enquanto o simulacro é tido como uma imitação imperfeita "originária para viver de uma falsa semelhança, que abre caminho a uma dessemelhança generalizada, a um afastamento progressivo e incontrolável com relação ao centro, à Ideia” (PERRONE-MOISÉS, 2005, p. 6).

É justamente nessa imperfeição que se orienta a poética do pós-modernismo. O simulacro, rejeitando os antigos aspectos e a semelhança, reproduz a diferença, revolta-se contra o poder constituído, inaugurando a vertigem do descentramento (PERRONE-MOISÉS, 2005, p. 7). O 
simulacro, ao não aceitar uma classificação hierárquica, anulando qualquer tentativa de demarcação, desestabiliza as fronteiras, integrando diversos discursos antes marginalizados.

A ausência de um centro regulador nos textos da modernidade levanta questões como a fidelidade da obra a uma verdade prévia, visto que ela não pode ser compreendida como um mero reflexo de um mundo externo. A fiel reprodução, por sua vez, cede espaço à produção. Assim, a produção crítica não está mais atrelada a paradigmas e modelos, podendo "tornar-se, ela própria, produção poética" (PERRONE-MOISÉS, 2005, p. 9). Queremos atentar, portanto, para a pertinência de análises tradicionais frente a estruturas que, ultrapassando conceitos rígidos e homogêneos, constituem a cultura pós-moderna.

\section{Nove noites: um universo de desconstrução do senso comum nas malhas da História}

É nesse contexto de desestabilização de fronteiras, não linearidade e questionamentos, que o romance Nove noites, do escritor brasileiro Bernardo Carvalho, se insere. Rompendo com as usuais dicotomias entre verdade e ficção, razão e objetividade, ao ficcionalizar um acontecimento verídico, Nove noites, enquanto discurso pós-moderno que instala e subverte as convenções das narrativas-mestras, evidencia que, por trás de toda construção cultural, há um sistema ideológico que detém e legitima o caráter representativo de toda obra. Contudo, ao invés de revitalizar tais processos significativos de sentido exclusivo e unitário, recuperando, assim a aura, a essência da criação artística sobre a qual nos fala, quase romanticamente, Benjamin (1985), temos uma reelaboração ilimitada e criativa da forma de organização de nossa experiência temporal sem pretender alcançar e estabelecer, através da negação dos mecanismos de funcionamento das estruturas do ato comunicativo, um sentido final homogeneizante e dogmático.

Mas, afinal, qual o enredo desse instigante e inquietante romance pós-moderno que, recorrendo às palavras de Hutcheon (2005, p. 3), em sua análise acerca da representação política do mundo contemporâneo, "works to 'de-doxify' our cultural representations and their undeniable political import" ${ }^{4}$ ?

Operando no jogo entre forma e significado, a prosa vencedora do prêmio Portugal Telecom e do prêmio literário da Biblioteca Nacional, tem como ponto de partida um

\footnotetext{
4 "trabalha contra a doxa romântica em nossas representações culturais e suas incontestáveis importações políticas" (Nossa tradução).
} 
acontecimento veraz: após permanecer nove noites entre os índios krahô, no interior do Tocantins, o jovem antropólogo americano Buell Quain, de apenas vinte e sete anos, suicida-se brutalmente às vésperas da Segunda Guerra Mundial, em 1939, quando regressava da aldeia para a cidade de Carolina, fronteira com o estado do Maranhão. Ao saber do ocorrido por meio de um artigo de jornal, sessenta e dois anos após o trágico e inesperado acontecimento, um dos narradores do romance, que é um jornalista e pode ser considerado uma espécie de alter-ego do escritor Bernardo Carvalho, como veremos mais adiante, decide desvendar esse obscuro episódio da antropologia brasileira e que permaneceu esquecido por muitos anos. A partir daí, inicia-se uma longa e sinuosa viagem nas paisagens devastadas do passado cujos alcances temporais e espaciais são desafiados por caminhos errantes, uma vez que "a verdade está perdida entre todas as contradições e disparates" (CARVALHO, 2002, p. 6), como nos adverte um dos narradores do romance. Dessa forma, configurando-se como um jogo no qual, paradoxalmente, não há vencedores, a prosa carvaliana se volta para as indeléveis e especulativas questões históricas que operam no limite entre o vivido e o relato, entre a escrita e a representação da rede conceitual das ações, evidenciando que a literatura, como discurso das possibilidades, é capaz de preencher, sem estabelecer um sentido final, as lacunas da História através do exercício da imaginação produtiva.

$\mathrm{Na}$ tentativa de reconstruir a história, o narrador-jornalista, que de certa forma representa a tradicional escrita da História, de Ranke ${ }^{5}$, em sua tentativa de reproduzir aquilo que realmente aconteceu, recorre a indivíduos históricos que conviveram com Buell Quain como Heloísa Alberto Torres, diretora do museu nacional e até mesmo Lévi-Strauss. É evidente que as referências a pessoas reais contribuem para aumentar a tensão entre verdade e imaginação. Qual a relação entre os nomes das pessoas na narrativa e na história? Se levarmos em consideração que, segundo Lyotard (apud Hutcheon, 1991, p. 196), eles são “designadores rígidos da realidade”, ou seja, que seus referentes são os mesmos no universo extraficcional e intradiegédico, vencemos o jogo. Mas será essa analogia tão confiável, se partimos da premissa que Nove noites é uma espécie de metaficção historiográfica, ou seja, um romance que nos lembra que "a própria história e a ficção são, ambos, termos históricos e suas definições e suas inter-relações são também determinadas historicamente e variam ao longo do tempo" (HUTCHEON, 1991, p. 141)? Acreditamos que não. Ela não nega, em hipótese alguma, o referente, apenas problematiza sua

\footnotetext{
${ }^{5}$ Leopold von Ranke, historiador alemão que, nos estudos mais recentes (La nouvelle histoire) sobre as questões simbólicas imbricadas na prática historiográfica, é considerado um representante do paradigma tradicional da história, isto é, da crença na objetividade e neutralidade do relato histórico.
} 
natureza. A metaficção historiográfica nos ensina que "em toda ficção os personagens históricos podem conviver com personagens ficcionais" (HUTCHEON, 1991, p. 197), pois ambos se referem a intertextos - históricos e literários -, ou seja, a entidades textualizadas e discursivas. A autorreflexidade dos romances pós-modernos sugere que "a linguagem não pode se prender diretamente à realidade, mas se prende basicamente a si mesma” (HUTCHEON, 1991, p. 201).

Sem sucesso, o narrador jornalista, segue em direção à aldeia Xingu. Embora não tenha havido grandes revelações sobre o caso, uma vez que os interesses dos índios recaem com mais intensidade nos objetos materiais do homem branco, esse episódio nos é de particular interesse, visto que as experiências do narrador-jornalista se aproximam, em vários aspectos, das vivenciadas pelo nosso autor-empírico. O narrador-jornalista do romance, como nos mostra a seguinte passagem, costumava viajar para o Xingu, com o pai: "Ninguém nunca me perguntou, e por isso nunca precisei responder que a representação do inferno, tal como imagino, também fica, ou ficava, no Xingu da minha infância" (CARVALHO, 2002, p. 53). Até aí nada de extraordinário, a não ser pelo fato de que na orelha do livro há uma foto do autor, aos seis anos de idade, de mãos dadas com um índio da tribo Xingu. Ficção, autobiografia, história, falsificação?

Embora não possamos (e não almejamos) fundar uma resposta unívoca, poderíamos dizer que, em meio a tantos questionamentos sobre a veracidade dos eventos inseridos nesse romance, o que está em questão é, antes, a historicidade dos fatos e sua inteligibilidade, sugeridas por uma descontinuidade estrutural com o tempo, do que a comprovação cientifica de uma verdade utópica e inquestionável mediante a adoção de critérios como falsificação, uma vez que "só existem verdades no plural, e jamais uma só Verdade; e raramente existe a falsidade per se, apenas as verdades alheias" (HUTCHEON, 1991, p. 146). Desse modo, mediante esse profícuo reconhecimento que evidencia a polêmica rejeição pós-moderna às representações "autênticas" ao considerar a escrita (seja ela literária ou pertencente ao campo da historiografia) um processo de adaptação, nos vemos obrigados a mudar nosso horizonte de expectativas e a aceitar que, na verdade, não existe um sentido final incontestável, mas um universo de múltiplas perspectivas.

Nesse sentido, após constantes tentativas visando à recuperação da totalidade da história do jovem antropólogo Buell Quain, ficam apenas especulações como em todo discurso histórico e literário autoconsciente dos limites de seus relatos. Assim, diante da incapacidade de conhecer o passado com um mínimo de certeza e em meio a diversas "verdades", o narrador-jornalista conclui que a única solução é escrever um romance, evidenciando o que dissera Tzvetan Todorov 
(apud HUTCHEON, 1991, p. 146): "a literatura não é um discurso que possa ou deva ser falso (...) é um discurso que, precisamente, não pode ser submetido ao teste de verdade; ela não é verdadeira nem falsa". Corroborando a citação, vemos em Nove noites a seguinte passagem:

[...] depois de meses lidando com papéis de arquivos, livros e anotações de gente que não existia, eu precisava ver um rosto, nem que fosse como antídoto à obsessão sem fundo e sem fim que me impedia de começar a escrever [...] com o medo de que a realidade seria sempre muito mais terrível e surpreendente do que eu podia imaginar [...] e que só se revelaria quando fosse tarde, com a pesquisa terminada e o livro publicado. Porque agora eu já estava disposto a fazer dela uma ficção (CARVALHO, 2002, p. 141).

\section{É possível concluir?}

Após o estudo da obra de Bernardo Carvalho à luz do panorama pós-moderno, foi possível verificar que adotar os pressupostos da crítica descritiva é manter e cultivar a hierarquia idealista frente a uma ficção crítica e produtiva. Crítica e produtiva, pois a poética pós-modernista contesta os preceitos de nossa ideologia dominante, desafiando a crença em um eu unificado e em uma consciência global através de questões como autoria e originalidade:

O factício e o simulacro se opõem no cerne da modernidade, no ponto onde esta acerta todas as suas contas, como se opõem dois modos de destruição. Pois há uma grande diferença entre destruir para conservar e perpetuar a ordem estabelecida das representações, dos modelos e das cópias, e destruir os modelos e as cópias para instaurar o caos que cria, que faz avançar os simulacros e levantar um fantasma - a mais inocente de todas as destruições, a do platonismo (DELEUZE, apud PERRONEMOISÉS, 2005, p. 10).

Pensar em noções cristalizadas como as do cânone, portanto, é o mesmo que negar as inúmeras possibilidades de efeitos de significação da complexidade e pluralidade da literatura contemporânea; é acreditar nos pressupostos idealistas da existência de um centro inspirador e regulador que detém e legitima o caráter representativo de toda obra, visto que "a ficção pósmoderna sugere que reescrever ou reapresentar o passado na ficção e na história é - em ambos os casos - revelá-lo ao presente, impedi-lo de ser conclusivo e teológico" (HUTCHEON, 1991, p. 147). Pensar de acordo com os rígidos conceitos solidificados pelo platonismo, portanto, é o 
mesmo que situar em inúmeros reducionismos uma literatura que é marcada pela transgressão e desconstrução do senso comum, literatura que, desde sua conceituação, sofre concorrência de relatos, o que evidencia seu caráter descentralizador, não- linear e descontínuo.

Gostaríamos, portanto, após essa breve articulação acerca dos dispositivos políticos e estéticos do pós-modernismo, imbricados na polêmica e produtiva relação dialógica entre os discursos literário e histórico, de encerrar nossas considerações no presente trabalho, mas desde já evocando novos desafios, com a já conhecida máxima de Marx: será que o sólido está finalmente se desmanchando no ar?

\section{Referências bibliográficas:}

AGAMBEN, Giorgio. O que é o contemporâneo? e outros ensaios. Chapecó, SC: Argos, 2009.

BENJAMIN, Walter. A obra de arte na era de sua reprodutibilidade técnica. In: Magia e técnica, arte e política. São Paulo: Brasiliense, 1985. . O anjo da história. Lisboa: Assírio e Alvin, 2008.

CARVALHO, Bernardo. Nove noites. São Paulo: Companhia de Bolso, 2010.

DELEUZE, Gilles. Logique du sens. Paris: Minuit, 1969.

EAGLETON, Terry. As ilusões do pós-modernismo. Rio de Janeiro: Zahar, 1998.

. Depois da Teoria: um olhar sobre os Estudos Culturais e o pós-modernismo. Rio de Janeiro: Civilização Brasileira, 2011.

HUTCHEON, Linda. Poética do pós-modernismo. Rio de Janeiro: Imago, 1991.

. The politics of postmodernism. London; New York: Routledge, 2005.

LIMA, Luiz Costa. História. Ficção. Literatura. Rio de Janeiro: Companhia das Letras, 2006.

PERRONE-MOISÉS, Leyla. Texto, crítica, escritura. 3. ed. São Paulo: Martins Fontes, 2005.

SANTOS, Jair Ferreira dos. O que é pós-moderno. 22. ed. São Paulo: Brasiliense, 1987.

SCHOLLHAMMER, Karl Erik. Ficção brasileira contemporânea. Rio de Janeiro: Civilização Brasileira, 2009.

TODOROV, Tzvetan. Introduction to Poetics. Minneapolis, University of Minnesota Press, 
1983.

Shadows of the present: a study on the political and aesthetic postmodern system

\begin{abstract}
Postmodernism, as a current trend in many different fields, has been analyzed by many critics who keep different positions regarding the problem. In spite of being accused of superficiality, of emptiness, in Terry Eagleton's words (1998), this political and cultural phenomenon have held all instances of rupture and questioning of the canon, provoking huge transformation in most areas. It is exactly this network of self-conscious changes that challenges Literary Theory in its quest for new methodologies that will be able to deal with political and aesthetic devices that this article intends to investigate. A critical study on Nove noites, by Bernardo Carvalho, aims at bringing to the discussion the main aspects of the postmodernist idea. This study will be centered in the dialogue between literary and historical discourses in which, without denying the particularities of each discourse, the specificities that connect history and literature will be verified, thus leading our reflection to the comprehension of the aspects of the temporal experience regarding the relations between present and past.
\end{abstract}

Key words: Postmodernism. Literature and History. Canon. 